\title{
TO DETERMINE THE FUNCTIONAL EFFICACY OF LED UNITS IN VARIOUS CLINICAL OFFICES
}

Kamal Nabhi ${ }^{1}$, Ajay Chhabra ${ }^{2}$, Varun Jindal ${ }^{3}$, Damanpreet ${ }^{4}$

${ }^{1}$ PG Student, Department of Conservative Dentistry \& Endodontics, Bhojia Dental College \& Hospital, Himachal Pradesh, India

${ }^{2}$ Professor and Head, Department of Conservative Dentistry \& Endodontics, Bhojia Dental College \& Hospital, Himachal Pradesh, India

${ }^{3}$ Reader, Department of Conservative Dentistry \& Endodontics, Bhojia Dental College \& Hospital, Himachal Pradesh, India

${ }^{4}$ Reader, Department of Conservative Dentistry \& Endodontics, Bhojia Dental College \& Hospital, Himachal Pradesh, India

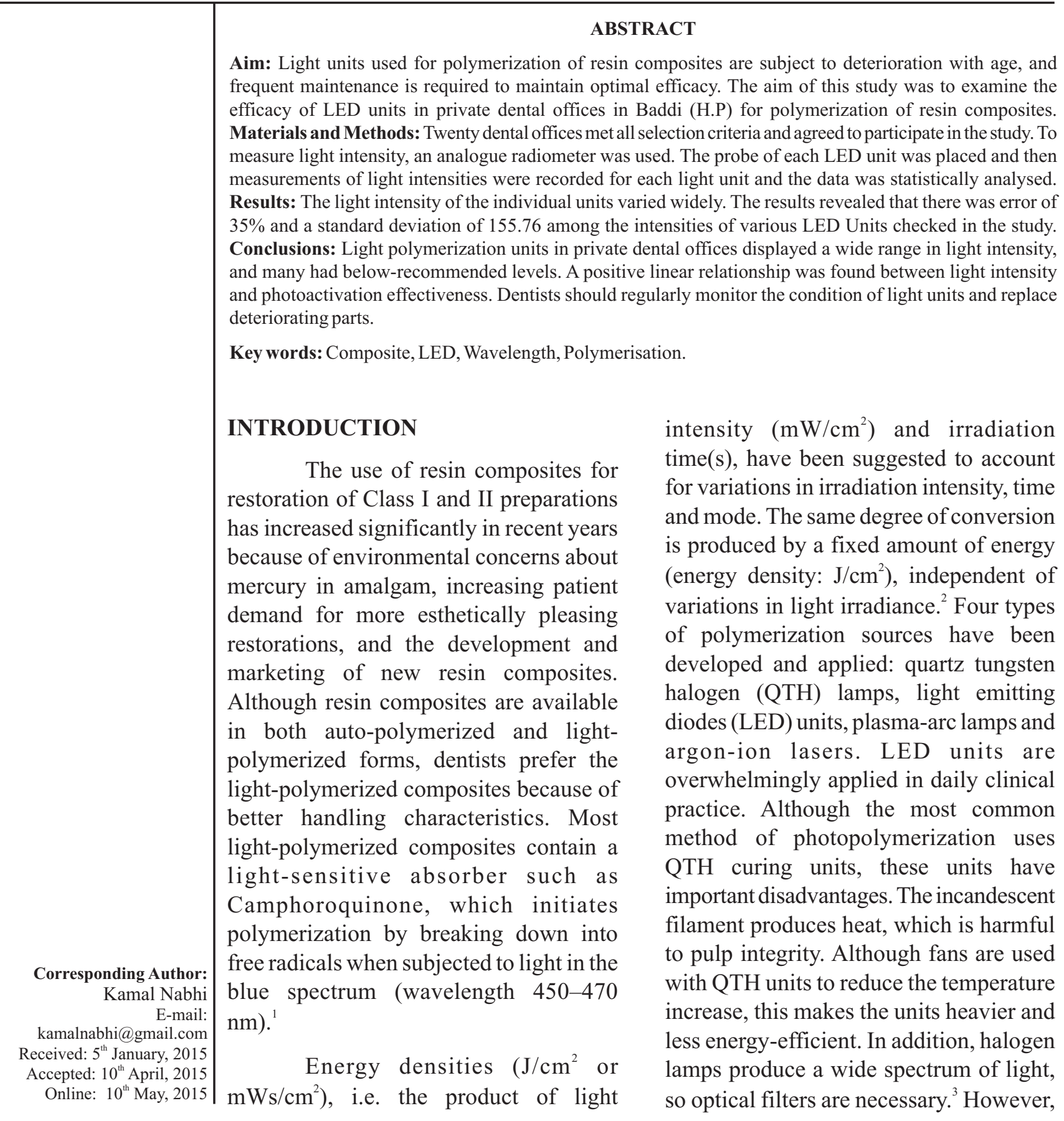


the bulb, reflector and filter of halogen LCUs degrade over time due to the operating temperatures and the large quantity of heat generated, resulting in a reduction of the curing effectiveness of halogen LCUs over time $^{4}$ (Figure 1).

LEDs use a combination of two different doped semiconductors instead of a hot filament. The spectral output of gallium nitride blue LED conveniently falls within the absorption spectrum of Camphoroquinone. Therefore, they do not require filters to produce blue light and they convert electricity into light more efficiently. They produce less heat so no cooling fan is required and they can be smaller and cordless. Moreover, LEDs can operate for thousands of hours with a constant light output in power and spectra. ${ }^{5}$

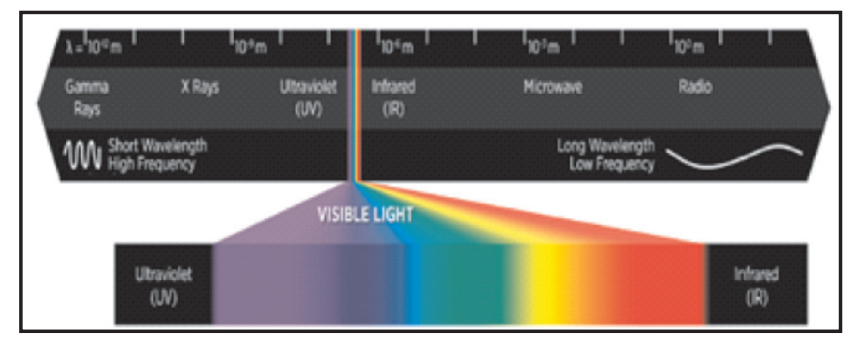

Figure 1: Electromagnetic spectrum illustrating Visible Light Spectrum

An adequate polymerization of resin composites is essential for the ultimate success of the restorations. The degree of cure of resin composite materials influences their mechanical properties, solubility, dimensional stability, color change and biocompatibility. ${ }^{6}$ According to Rueggeberg, light sources with intensity values less than $233 \mathrm{~mW} / \mathrm{cm}^{2}$ should not be used because of their "poor cure characteristics." Light units with intensities of less than $200 \mathrm{~mW} / \mathrm{cm}^{2}$ or less than $300 \mathrm{~mW} / \mathrm{cm}^{2}$ as inadequate, unusable or unsuitable. ${ }^{1}$ The proper characterization of LEDs became of central importance for many LED manufacturers and users. At present many manufacturers produce LEDs of different light colour and mechanical structure. Without a unified characterization of the LED products the user is unable to select the unit which would suit his application best. ${ }^{8}$ In addition to the correct wavelength, sufficient light intensity and exposure time are also important for optimal polymerization. ${ }^{5}$ Therefore the aim of this study was to check the functional efficacy of LED units in various clinical offices .

\section{MATERIALS AND METHODS}

The following selection criteria were used to identify various dental offices for participation in this study.

- The dentist operating the office had to be a general practitioner or a specialist.

- The dental office had to be accessible by public transportation.

- The light polymerization unit(s) in the offices should be LED Cordless Units.

- The dentist had to routinely use resin composites for restoration of posterior teeth.

For each office that met selection criteria, the dentist was contacted by telephone, at which time the study was explained, the dentist's interest was determined, and the methods were briefly explained. This process was repeated until 20 dental offices meeting the previously stated criteria had agreed to participate. Altogether, 40 offices were initially contacted. Once agreement to participate was reached, an appointment was made for a visit to the office at a mutually convenient time. Upon arrival at each office, the purpose and methods of the study were explained to them in detail. The number of LED light units in the office and information about each unit, including approximate date of purchase and service history, as provided by office personnel or dentist, were recorded.

To measure light intensity, an analogue radiometer (BLUE LUXAR), with a range from 0 to $1,000 \mathrm{~mW} / \mathrm{cm}^{2}$, was used (Figure 2). According to the manufacturer this meter detects light in the wavelength range of 400 to $500 \mathrm{~nm}$. Each day before visiting the dental office, the light radiometers were examined against another light radiometer to ensure consistency of readings. At each office, the probe of each LED was cleaned before placing on intensitometer. The probe of each LED unit was placed and then measurement of light intensity were recorded for each light unit. ${ }^{1}$ One of the LED Unit among twenty Clinics was not working at that time, so the readings were taken for nineteen LED Units. To conceal the identity of Clinics, they are denoted by the number. The data was collected (Table 1) and statistically analysed.

One of the LED Unit among twenty Clinics was not working at that time, so the statistical analysis 


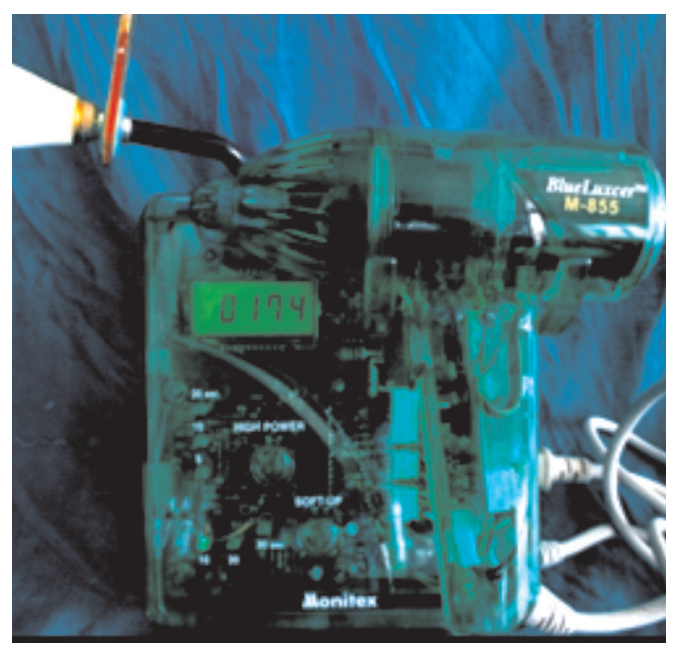

Figure 2: Intensitometer taking reading of LED unit

was done for nineteen values. The results (Table 2) revealed that there was error of $35 \%$ in the intensities of various LED Units. It also depicted that there is a standard deviation of 155.76 among the intensities of various LED Units included in the study.

\section{RESULTS}

Table 1: Depicting the readings of intensities of LED Units of various clinics

\begin{tabular}{|l|l|}
\hline Names Of Clinics & $\begin{array}{c}\text { Readings of } \\
\text { Intensities }\end{array}$ \\
\hline First dental clinic & 480 \\
\hline Second dental clinic & 174 \\
\hline Third dental clinic & 390 \\
\hline Fourth dental clinic & 508 \\
\hline Fifth dental clinic & 1128 \\
\hline Sixth dental clinic & 560 \\
\hline Seventh dental clinic & 490 \\
\hline Eighth dental clinic & 520 \\
\hline Eleventh dental clinic & 434 \\
\hline Twelfth dental clinic & 680 \\
\hline Thirteenth dental clinic & 460 \\
\hline Fouteenth dental clinic & 440 \\
\hline Fifteenth dental clinic & 530 \\
\hline Seventeenth dental clinic & 520 \\
\hline Eighteenth dental clinic & 500 \\
\hline Nineteenth dental clinic & 560 \\
\hline Twentieth dental clinic & 780 \\
\hline
\end{tabular}

Table 2: Depicting the Statistical Analysis of the study

\begin{tabular}{|l|l|c|c|c|}
\hline \multicolumn{5}{|c|}{ SAMPLE STATISTICS } \\
\hline & $\mathbf{N}$ & Mean & $\begin{array}{c}\text { Std. } \\
\text { Deviation }\end{array}$ & $\begin{array}{c}\text { Std. } \\
\text { Error } \\
\text { Mean }\end{array}$ \\
\hline VALUES & 19 & 553.00 & 155.761 & $\mathbf{3 5 . 7 3 4}$ \\
\hline
\end{tabular}

\section{DISCUSSION}

Postoperative sensitivity may occur because of partial dissolution of unpolymerized material at the tooth-restoration interface, and recurrent caries along the interface may occur. Inferior mechanical properties of the restoration may result in excessive wear or possibly bulk fracture of the composite..$^{9-12}$ In spite of previously published reports about the intensity of light emitted from polymerization units used in private dental offices, ${ }^{9-12}$ the present study indicated continued wide variation in light intensity in dental offices including some offices with units emitting light below minimum operational levels. As light intensity is directly associated with the polymerization of resin composites $^{10}$, low-intensity values are of concern. Inadequate light polymerization of resin composite restorations might cause a number of clinical problems. $^{11}$

Optical safety for LEDs, lamps and other light sources refers to the prevention of potential hazards caused by optical radiation (electromagnetic radiation of wavelengths ranging from $100 \mathrm{~nm}$ to $1 \mathrm{~mm}){ }^{13}$ Effects on the eyes as well as the skin are considered, including people with a higher sensitivity to light exposure. The light output from all units is different in several respects. Not all wavelengths of the emitted light are useful for the composite's curing process. $\mathrm{Cook}^{14}$ found the light between $410 \mathrm{~nm}-500 \mathrm{~nm}$ was the most effective. Between $410 \mathrm{~nm}-500 \mathrm{~nm}$ the LED has $40 \%$ of the power output. Due to the smaller light guide tip, however, the irradiance produced by the LED is $70 \%$. Ninety-five per cent of the total flux for the LED lies between $410 \mathrm{~nm}-500 \mathrm{~nm}$. The flux from the LED peaks at $460 \mathrm{~nm}$ and is concentrated over a much narrower wavelength band. Depth of cure is a significant first step as this depends on the quantity of useful blue light energy that can be applied to a given volume of composite in a reasonable time. Blue light in different parts of the absorption spectrum of Camphorquinone has a different effectiveness, and that light near to the absorption peak is more effective at curing. ${ }^{15}$

The high intensity LEDs plays an important role in therapeutic application, aggregating the technology of solid-state devices and a variety of electronic converters that supplying these long-lifetime devices for controlling the output current, output 
power, duty cycle and other parameters that directly interfere in luminous efficiency in the wavelength and the response of treatments applied to human health. ${ }^{16}$ The penetration of light in human tissue is linked to the wavelength, that is, greater the length greater will be their interaction in human tissues as shown in the Figure 3, since these wavelengths respect the range of visible light. Therefore, the application of a particular wavelength directly connected with the color should be used cautiously. ${ }^{15}$

It is important to emphasize that the performance of the light sources can be decreased by the inadequate maintenance of the optic fiber and light literature has described that this clinical situation can result in aesthetic involvement, marginal microleakage, and decrease of the physical and biological properties of the resin composites. Based on the forementioned discussion, it can be affirmed that the conservation state of the light source directly interfered in the photoactivation effectiveness. It is necessary to have the periodical maintenance of the light sources, as their conservation state is related to the power intensity and consequently with the polymerization effectiveness. Therefore, the clinic staff must be aware of these requirements regarding the use of the light sources and the need of a preventive

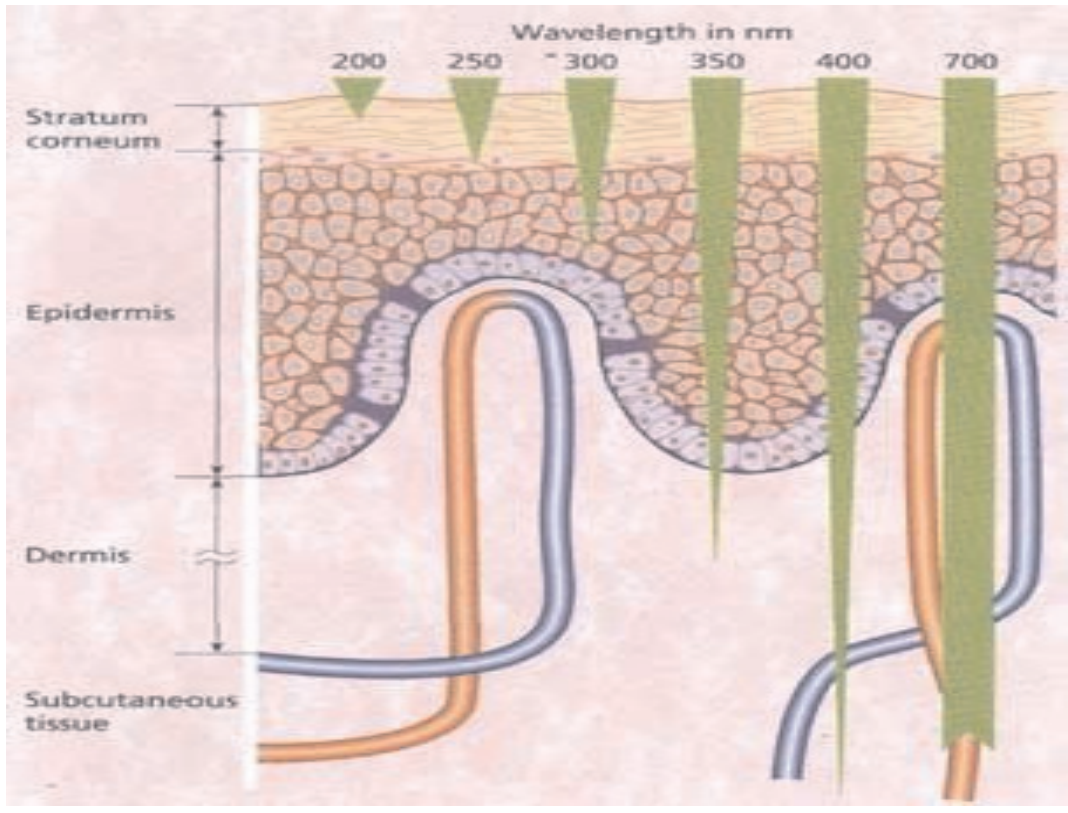

Figure 3: Action of color and penetration depth in human tissue.

transmitter tip. It is important to consider that the inadequate conservation of the light sources is related to a smaller intensity of light emission. This premise was corroborated by the results obtained by this present study. It can be affirmed that the conservation state of the light sources was directly related to the power density observed. The adequate photopolymerization of a resin composite is linked to the light intensity and to the exposure time.LED sources required a minimum light intensity of $300 \mathrm{~mW} / \mathrm{cm}^{2}$ and at least 20 seconds of exposure time. ${ }^{15}$

This present study observed that $35 \%$ of the light sources did not exhibit proper wavelength. The maintenance protocol to achieve the photopolymerization effectiveness. ${ }^{17}$

\section{CONCLUSION}

The clinical effectiveness of the light sources was dependent on their conservation state and power density, which were inadequate for most of the sources tested.

The light sources in clinical use exhibited similar conditions of conservation state and power density, regardless the clinic where they were located. ${ }^{17}$

\section{REFERENCES}

1. Omar El-Mowafy, Donald W. Lewis, Babak Shokati, Osama 
Soliman, Jaffer Kermalli,Avedis Encioiu,Fatma Rajwani,Rema Zawi: Efficacy of Halogen Photopolymerization Units in Private Dental Offices in Toronto. J Can Dent Assoc 2005; 71(8): 587

2. Norbert kramer, Ulrich lohbauer, Franklin Garcia-Godoy \& Roland Frankenberger: Light curing of resin-based composites in the LED era: American Journal of Dentistry.2008;21(3): 135-142.

3. Christos Rahiotis, Katerina Patsouri, Nick Silikas and Afrodite Kakaboura: Curing efficiency of high-intensity lightemitting diode (LED) Devices. Journal of Oral Science.2010;52(2):187-195.

4. Oya Bala, Hacer Deniz Arisu, Bagdagul Helvacioglu Kivanc, Sara Samur. Effect of different light curing systems on the shear bond strength of resin-modified glass ionomer cement and polyacid-modified composite resin. Journal of Dentistry and Oral Hygiene. 2009;1(2):17-21.

5. Laura Ceballos, Maria Victoria Fuentes, Hector Tafalla, Alvaro Martínez, Josefa Flores, Jesus Rodriguez. Curing effectiveness of resin composites at different exposure times using LED and halogen units. J Clin Exp Dent.2009;1(1):8-13.

6. Optical Safety of LEDs: Building Technologies Office SolidState Lighting Technology Fact Sheet: US Department of Energy:Energy Efficiency and Renewable Energy:J2013:1-4.

7. Rueggeberg FA, Caughman WF, Curtis JW Jr. Effect of light intensity and exposure duration on cure of resin composites.Oper Dent 1994;19(1):26-32.

8. www.inphora.com/LED_intensity.pdf: the Commission Internationale De L'Eclairage (CIE): Measuring Average LED Intensity;1-9.
9. R.W.Mills, K.D. Jandit, S.H.Ashworth. Dental Composite depth of cure with halogen and blue light emitting diode technology. Br Dent J 1999; 186(8):1-4.

10. Mauro C. Moreira, Ricardo Prado and Alexandre Campos. Application of High Brightness LEDs in the Human Tissue and Its Therapeutic Response. Journal of Applied Biomedical Engineering 2000;1-14.

11. Laís Santos Goncalves, Mercia Braulio Goncalves, Marilia Morais Martins. Clinical Effectiveness of light-curing units of the School of Dentistry of the Federal University of Goias. RSBO 2013; 10(3):228-33.

12. John W. Farah,John M. Powers. The Dental Advisor"Improved Patient Care through Research" 2004; 21(6): 1-2. www.dentaladvisor.com

13. www.globallightingassociation.org. Optical and Photobiological Safety of LED, CFL, and Other High Efficiency General Lighting Sources. 1-22.

14. Cook WD. Spectral distribution of dental photopolymerization sources. J Dent Res 1982; 61:1436-1438.

15. R. W. Mills, K. D. Jandt S. H. Ashworth. Dental composite depth of cure with halogen and blue light emitting diode technology. British Dental Journal.1999;186(8): 388-391.

16. Mauro C. Moreira, Ricardo Prado and Alexandre Campos. Application of High Brightness LEDs in the Human Tissue and Its Therapeutic Response. Applied Biomedical Engineering: www.intechopen.com: 1-19.

17. Lais Santos Goncalves, Mercia Braulio Goncalves, Marilia Morais Martins, Gersinei Carlos de Freitas, Lawrence Gonzaga Lopes,Terezinha Jesus Esteves Barata. Clinical effectiveness of light-curing units of the School of Dentistry of the Federal University of Goias. RSBO 2013; 10(3):228-33.

Source of Support: Nil, Conflict of Interest: None Declared 